\title{
CHARACTERIZATION OF VARIOUS VIRULENCE PROPERTIES OF DRUG-RESISTANT KLEBSIELLA ISOLATES: AN IN VITRO STUDY AMONG "SUPERBUGS"
}

\author{
JITENDRA CHANDRA DEVRARI, VIDYA PAI* \\ Department of Microbiology, Yenepoya Medical College, Yenepoya University, Mangalore, Karnataka, India. \\ Email:Micro_vidya7417@rediffmail.com
}

Received: 27 November 2017, Revised and Accepted: 26 December 2017

\section{ABSTRACT}

Objective: The objective of this study was to evaluate the various virulence factors among all extended-spectrum beta-lactamase (ESBL)-producing Klebsiella isolates.

Methods: Klebsiella species ( $\mathrm{n}=201)$ isolated from various non-repeated clinical samples from October 2016 to May 2017 were collected and identified by biochemical method and confirmed by BD Phoenix. Antibiotic susceptibility test was performed by Kirby-Bauer disc diffusion method, and ESBL detection was done by combined disc diffusion method. Capsule detection was done by nigrosin dye staining, hypermucoviscosity was done by string test, biofilm was performed by microtiter plate assay, and hemagglutination was performed with human erythrocytes treated with tannic acid.

Results: Among 201 ESBL-producing Klebsiella isolates, $63.2 \%$ were multidrug resistance and 24.4\% were extensively drug-resistant. Among these isolates, Klebsiella infection is more in older patients. All isolates were (100\%) positive for capsule and siderophores production. Of all 201 isolates, 14 (7\%) were strong, 61 (30.3\%) were moderate, and 104 (51.8\%) were weak biofilm producers. Among these isolates, 36 (17.9\%) were type 1 fimbriae, 140 (69.7\%) were type 3 fimbriae, and only 17 (8.5\%) were positive for hypermucoviscosity.

Conclusion: Several virulence factors were studied, in which biofilm with fimbriae is the main cause for the resistance of antibiotics. Bacterial resistance profile found to be high with ESBL production and multiple drug resistance in the majority of the Klebsiella isolates, which is a result of improper antibiogram schedule and their virulence property.

Keywords: Klebsiella species, Capsule, Biofilm, Hemagglutination, Hypermucoviscosity, Siderophores, Multidrug resistance.

(c) 2018 The Authors. Published by Innovare Academic Sciences Pvt Ltd. This is an open access article under the CC BY license (http://creativecommons. org/licenses/by/4. 0/) DOI: http://dx.doi.org/10.22159/ajpcr.2018.v11i4.23965

\section{INTRODUCTION}

Klebsiella is Gram-negative bacilli causing many infections such as urinary tract infections, respiratory infections, and bacteremia, whereas infections such as endophthalmitis and pyogenic liver abscess in immunocompromised individuals. Pathogenicity of Klebsiella species is due to the presence of many virulence factors that allow it to attack the immune system of host and cause different kind of diseases. Some of these virulence factors are as follows: Biofilm formation, hypermucoviscosity, capsule synthesis, fimbriae (adhesions), siderophores (iron uptake), and lipopolysaccharide formation.

Biofilm producing bacteria are responsible for many recurrent infections and difficult to eradicate. They exhibit resistance to antibiotics by various methods such as restricted penetration of antibiotic into biofilms and expression of resistance genes [1]. Most infectious diseases caused by bacteria are known to be regulated by quorum-sensing mechanisms which in turn regulate the pathogenicity [2]. Biofilm formation of bacteria is an organized matrix adhering to the surface and with each other and provides enhanced tolerance to antibiotics to the pathogens $[3,4]$.

Hypermucoviscosity is a new virulent variant of Klebsiella species which has emerged in the Asian Pacific Region, and it is now well recognized in Western countries as well. It has ability to cause serious, life-threatening community-acquired infections such as liver abscess, pneumonia, meningitis, and endophthalmitis. It has the ability to metastatically spread an unusual feature for enteric Gram-negative bacilli in the non-immunocompromised host [5].

Klebsiella has evolved high-affinity iron assimilation systems called siderophores, which are small ligands that are specific for ferric iron, and thus supply iron to the bacterial cells. Fimbriae, capsules, and lipopolysaccharide are the virulence factors mostly involved in the ability of Klebsiella isolates to help them to grow as biofilm [6]. Klebsiella has express two types of fimbrial adhesins, type 1 and type 3 fimbriae. Type 1 fimbriae are found in the majority of Enterobacteriaceae; they mediate adhesion to mannose containing structures and type 3 fimbriae are present in practically all Klebsiella isolates and mediate adhesion to several cell types in vitro [7].

\section{METHODS}

A prospective 1 year study was conducted at the Department of Microbiology, Yenepoya Medical College, Mangalore, India. A total of 201 non-duplicate extended-spectrum beta-lactamase (ESBL)-producing Klebsiella isolates were processed from October 2016 to October 2017 after obtaining Ethical Clearance from Institutional Ethics Committee.

Klebsiella spp. were identified using standard methods based on Gram staining, culture on blood agar and MacConkey agar media, catalase reaction, oxidase test, and biochemical reactions such as indole, MR, VP, citrate utilization, TSI agar, urease production, and mannitol motility test [8]. Antibiotic sensitivity testing of Klebsiella spp. was done by Kirby-Bauer disc diffusion method according to the CLSI guidelines 2016 [9].

\section{Capsule detection}

The presence of capsule was investigated by staining with nigrosin, a loopful of overnight bacterial colony was transferred on a dry and clean slide, then gently mixed with nigrosin and allowed to dry in air, then rinsed with water, the slide was stained with methylene blue for $2 \mathrm{~min}$ and allowed to air dry, then the slide was gently washed with water, under light 
microscope, the nigrosin stain provides a dark background to unstained capsule and methylene blue stain provides blue color to the cells [10].

\section{Biofilm assay}

Overnight grown cultures Klebsiella species were diluted in 1:20 with fresh medium of brain heart infusion (BHI) with $1 \%$ sucrose. Transfer $200 \mu \mathrm{l}$ of each diluted bacterial inoculums to the wells of microtiter plates and only BHI with $1 \%$ glucose broth to the control wells and incubated overnight at $37^{\circ} \mathrm{C}$. After incubation, the supernatant was aspirated from the wells of microtiter plates and washed once with $3 \mathrm{ml}$ of phosphate buffer saline (PBS). Microtiter plates were dried and $200 \mu \mathrm{l}$ of sodium acetate (2\%) was added to each well and kept for 15-20 min at room temperature (RT). Methanol was discarded from the wells and microtiter plates were dried. $0.1 \%(\mathrm{w} / \mathrm{v})$ crystal violet $(\mathrm{CV})$ was added in wells of each well and allowed to incubate at RT for 15 min; then, CV was discarded from each well. Again plates were washed with PBS for 2-4 times and plates were dried. Finally, to remove excess of CV, $200 \mu \mathrm{l}$ of ethanol (95\%) was added to the wells and kept at RT for $15 \mathrm{~min}$. Final reading was taken with ELISA reader at $590 \mathrm{~nm}$ wavelength [11].

\section{Hemagglutination assay}

The hemagglutination was detected by clumping of erythrocytes by fimbriae of bacteria in the presence of D-mannose. This test was carried out as per the direct bacterial hemagglutination test - slide method and mannose-sensitive (MS) and mannose-resistant hemagglutination tests. The strains of Klebsiella were inoculated on BHI broth and incubated at $37^{\circ} \mathrm{C}$ for 48 hours for full fimbriation. Hemagglutination tests were made with "tannic acid" treated "A" positive red blood cells. The red blood cells were washed thrice in normal saline. For the test with tanned red cells, washed red cells were treated with $0.003 \%(\mathrm{w} / \mathrm{v})$ tannic acid for $10 \mathrm{~min}$. At $37^{\circ}$ and then twice washed before making up to a $3 \%$ red blood cells (RBCs) (v/v) suspension in saline $(0.85 \%, \mathrm{w} / \mathrm{v}, \mathrm{NaCl})$. These cells showed a beginning of agglutination while in the tannic acid but, after washing, gave a suspension which was not autoagglutinable during continuous mixing for $15 \mathrm{~min}$ on the concavity slide. They were used immediately or within a week when stored at $3-5^{\circ} \mathrm{C}$. The slide hemagglutination test was carried out on a multiple concavity slide. One drop of tanned RBC suspension was added to a drop of broth culture of suspension containing about $10^{10}-10^{11}$ bacilli/ml, prepared by centrifuging a broth culture, decanting the supernatant liquid and mixing the deposit with the residual liquid. Mixing on the slide was continued at RT during $15 \mathrm{~min}$ on a rocking machine which tilted to and fro 50 times/min. Coarse hemagglutination was often seen within $1 \mathrm{~min}$, but with weakly active cultures only a fine granularity appeared after 5-10 min. The MS of each reaction was observed by adding a small drop of a $2 \%(w / v)$ D-mannose solution to the drop of red cells before adding the bacilli; the final mannose concentration (0-5\%) completely prevented MS hemagglutination. The presence of clumping was taken as positive for hemagglutination. MS hemagglutination was detected by the absence of hemagglutination in a parallel set of test in which a drop of $2 \% \mathrm{w} / \mathrm{v}$ D-mannose was added to the red cells and a drop of broth culture. Mannose-resistant (MR) hemagglutination was detected by the presence of hemagglutination of 3\% "A" group human RBC in the presence of 2\% D-mannose. ATCC Escherichia coli 25922 strain was used as a negative control for MS hemagglutination assay (MSHA) and a known strain of Klebsiella repeatedly giving positive was taken as control for MR hemagglutination assay (MRHA) assay [12].

\section{Hypermucoviscosity testing}

Klebsiella isolates will be separated and cultivated on blood agar medium (containing $5 \%$ sheep blood) and incubated at $37^{\circ} \mathrm{C}$ for $24 \mathrm{~h}$. After incubation, investigate the HV using standard bacteriological loops through the bacterial colony. Colonies which will draw $>5 \mathrm{~mm}$ will be considered as positive [5]

\section{Siderophores production assay}

Nutrient agar supplemented with $200 \mathrm{mM}$ of 2.2'-dipyridyl was used as iron-restricted agar medium. All bacterial isolates were streaked on agar plates and then incubated at $37^{\circ} \mathrm{C}$ for $24 \mathrm{~h}$. Any bacterial growth was considered as positive results for the ability of bacteria to siderophores production [13].

\section{Statistical analysis}

Descriptive statistics like frequency (\%) were used for analysis. Variables were expressed as percentages. All the data were expressed as table diagrams.

\section{RESULTS}

A total of 201 ESBL-producing Klebsiella isolates were collected from different clinical sample, i.e., $71(35.3 \%)$ were pus, $40(19.9 \%)$ were urine, 36 (17.9\%) were sputum, 26 (12.9\%) were blood, 12 (6\%) were ventilator aspirates, 6 (2.9\%) were endotracheal aspirates, $4(2 \%)$ were body fluid, 4 (2\%) were high vaginal swab, and $2(0.9 \%)$ were bronchoalveolar lavage samples. According to age and gender wise, all 201 isolates were distributed as shown in Table 1.

Among all isolates, 127 (63.2\%) were multidrug-resistant (MDR) and $49(24.4 \%)$ were extensively drug-resistant (XDR) as shown in Table 2.

Table 1: Age and gender wise distribution of ESBL-producing Klebsiella isolates

\begin{tabular}{llll}
\hline Age group (years) & Male & Female & Total (\%) \\
\hline $0-10$ & 16 & 2 & $18(9)$ \\
$11-20$ & 5 & 3 & $8(4)$ \\
$21-30$ & 13 & 7 & $20(9.9)$ \\
$31-40$ & 15 & 5 & $20(9.9)$ \\
$41-50$ & 17 & 19 & $36(17.9)$ \\
$51-60$ & 33 & 13 & $46(22.9)$ \\
$61-70$ & 28 & 12 & $40(19.9)$ \\
$>70$ & 10 & 3 & $13(6.5)$ \\
Total & $137(68.2)$ & $64(31.8)$ & $201(100)$ \\
\hline
\end{tabular}

ESBL: Extended-spectrum beta-lactamase

Table 2: Prevalence and distribution of virulence factors according to clinical samples

\begin{tabular}{|c|c|c|c|c|c|c|c|}
\hline \multirow[t]{2}{*}{ Samples $(n=201)$} & \multirow[t]{2}{*}{ BF } & \multirow[t]{2}{*}{ Capsule } & \multirow[t]{2}{*}{ HMV } & \multirow[t]{2}{*}{ HA } & \multirow[t]{2}{*}{ Siderophores } & \multicolumn{2}{|c|}{ AST patterns } \\
\hline & & & & & & MDR & XDR \\
\hline Pus (71) & 64 & 71 & 7 & 66 & 71 & 47 & 16 \\
\hline Sputum (36) & 31 & 36 & 4 & 32 & 36 & 26 & 2 \\
\hline Blood (26) & 24 & 26 & 1 & 22 & 26 & 12 & 10 \\
\hline Ventilator aspirate (12) & 9 & 12 & 1 & 09 & 12 & 8 & 4 \\
\hline Body fluid (4) & 4 & 4 & - & 3 & 4 & 1 & 3 \\
\hline $\operatorname{HVS}(4)$ & 4 & 4 & - & 3 & 4 & 4 & - \\
\hline ET aspirate (6) & 6 & 6 & - & 6 & 6 & 4 & 2 \\
\hline BAL (2) & 0 & 2 & - & 1 & 2 & 1 & 1 \\
\hline Total (\%) & 179 (89) & $201(100)$ & $17(8.5)$ & $176(87.6)$ & $201(100)$ & 127 (63.2) & $49(24.4)$ \\
\hline
\end{tabular}

HVS: High vaginal swab, ET: Endotracheal aspirate, BAL: Bronchoalveolar lavage, BF: Biofilm formation, HMV: Hypermucoviscosity, HA: Hemagglutination assay, MDR: Multidrug-resistant, XDR: Extensively drug-resistant 
All 201 (100\%) Klebsiella isolates were positive for capsule formation and siderophores production; whereas 17 (8.5\%) isolates were positive for hypermucoviscosity (Fig. 1) and 184 (91.5\%) were negative.

In case of biofilm production out of 201, 14 (7\%) were strong, 61 (30.3\%) were moderate, 104 (51.8\%) were weak, and 22 (10.9\%) were non-biofilm producers as shown in Table 3 and Fig. 2.

For fimbriae detection, 36 (17.9\%) were MSHA (type 1 fimbriae), 140 (69.7\%) were MRHA (type 3 fimbriae), and 25 (12.4\%) were nonhemagglutinated as shown in Table 4 and Fig. 3.

\section{DISCUSSION}

Klebsiella infections occur in humans of all ages; however, the highest risk groups appear to be elderly, infants, and the immunocompromised. One or more virulence factors may contribute to pathogenicity in humans. In this present study, bacterial resistance profile found to be high with ESBL production and drug resistance of the Klebsiella isolates, i.e., $63.2 \%$ were MDR and $24.4 \%$ were XDR, which might be because of their virulence property and other nosocomial factors.

Klebsiella infection was highest in number, i.e., 46 (22.9\%) in age group (years) 51-60, followed by 40 (19.9\%) in 61-70, $36(17.9 \%)$ in $41-50$, $20(9.9 \%)$ in $21-30$ and $31-40$ both, $18(9 \%)$ in $0-10,13(6.5 \%)$ in $>70$, and $8(4 \%)$ in 11-20. The results of the present study indicate that incidence of Klebsiella infection is more in older patients which might be due to the low immunity.

This study showed all isolates (100\%) have capsule (which will give to their colonies mucoid appearance) and siderophores production. Similar results have been reported from the other countries in 2008 and $2016[10,14]$ in which both capsule and siderophores were $100 \%$.

Table 3: Biofilm results of ESBL-producing Klebsiella isolates

\begin{tabular}{llll}
\hline $\begin{array}{l}\text { Klebsiella } \\
\text { isolates (n=201) }\end{array}$ & Strong (\%) & Moderate (\%) & Weak (\%) \\
\hline Pus & 3 & 23 & 38 \\
Urine & 4 & 12 & 21 \\
Sputum & 3 & 10 & 18 \\
Blood & 4 & 6 & 14 \\
Ventilator aspirate & - & 2 & 7 \\
Body fluid & - & 3 & 1 \\
High vaginal swab & - & 1 & 3 \\
ET aspirate & - & 4 & 2 \\
Bronchoalveolar & - & - & - \\
lavage & & & $104(51.8)$ \\
Total & $14(7)$ & $61(30.3)$ & \\
\hline
\end{tabular}

ESBL: Extended-spectrum beta-lactamase

Table 4: Fimbriae detection in Klebsiella isolates

\begin{tabular}{llll}
\hline $\begin{array}{l}\text { Klebsiella } \\
\text { isolates (n=201) }\end{array}$ & $\begin{array}{l}\text { Type 1 } \\
\text { fimbriae (MSHA) }\end{array}$ & $\begin{array}{l}\text { Type 3 } \\
\text { fimbriae (MRHA) }\end{array}$ & NHA \\
\hline Pus & 12 & 54 & 5 \\
Urine & 8 & 26 & 6 \\
Sputum & 7 & 25 & 4 \\
Blood & 4 & 18 & 4 \\
Ventilator & 2 & 7 & 3 \\
aspirate & & 3 & 1 \\
Body fluid & - & 2 & 1 \\
High vaginal & 1 & & \\
swab & & 4 & 0 \\
ET aspirate & 2 & 1 & 1 \\
Bronchoalveolar & - & 140 (69.7) & $25(12.4)$ \\
lavage & &
\end{tabular}

MSHA: Mannose sensitive hemagglutination assay, MRHA: Mannose-resistant hemagglutination assay
Hypermucoviscosity is an another emerging virulence factor which is a main cause of endophthalmitis and pyogenic liver abscess which has been described in several other studies $[5,15]$, and in the present study, we found that this virulence factor was present in pus, urine, sputum, and blood samples which is in accordance with other studies [10]. In the present study, hypermucoviscosity was found in $8.5 \%$ Klebsiella isolates which is an emerging virulent trait and alarming situation around the world; however, much higher percentage, i.e., 62.5\% [10] was reportedfrom other studies as compared to our study.

In fimbriae detection, we found that in Klebsiella infection type 3 fimbriae $(69.7 \%)$ are more frequent as compared to the type 1 fimbriae (17.9\%). Similar results have been reported in a study [16] in which type 3 are more frequent in Klebsiella infection. In a study done in 2013 [17] had reported that type 1 fimbriae were 57.4\% and type 3 fimbriae were 14.28\%; however, another study done in 2000 [18] reported type 1 fimbriae (86\%) and type 3 fimbriae was $70 \%$. According to Schroll et al. [3] reported that type 3 fimbriae are more essential compared to type 1 fimbriae for biofilm production.

In the present study, several virulence factors were studied, in which biofilm with fimbriae is the main cause for the resistance of antibiotics. Total $89 \%$ isolates had produced biofilms in which 14 (7\%) were strong, 61 (30.3\%) were moderate, and 126 (51.8\%) were weak. A study reported a much lesser percentage $63 \%$ of biofilm production in 2012 [19] which were not similar to the present study.

\section{CONCLUSION}

The rising trend of multiple drug-resistant is seen over the successive years, which is an alarming situation; it could be due to the presence of different types of virulence factors associated with their genes along with the drug-resistant genes, which would be more active in people

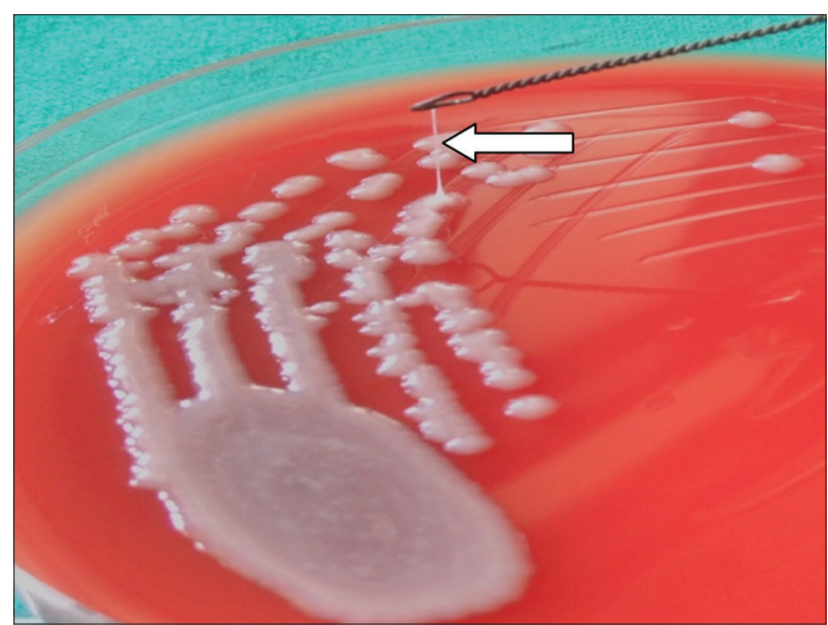

Figure 1: Hypermucoviscosity assay by string test (White arrow head is showing $>5 \mathrm{~mm}$ string formation i.e., Hypermucoviscosity positive).

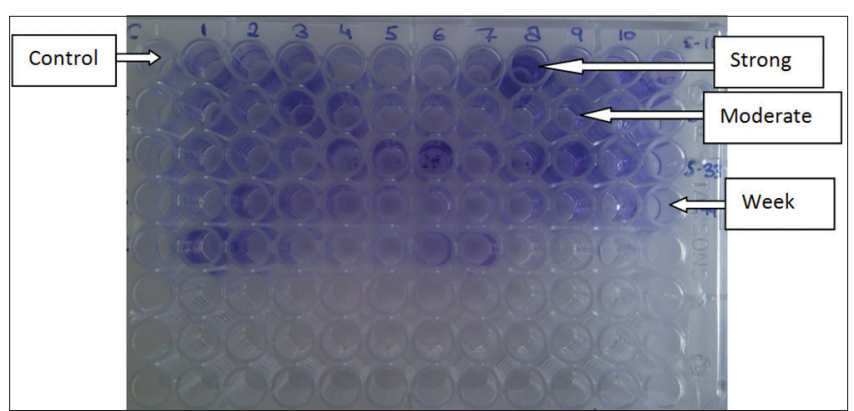

Fig. 2: Biofilm production by microtiter plate method 


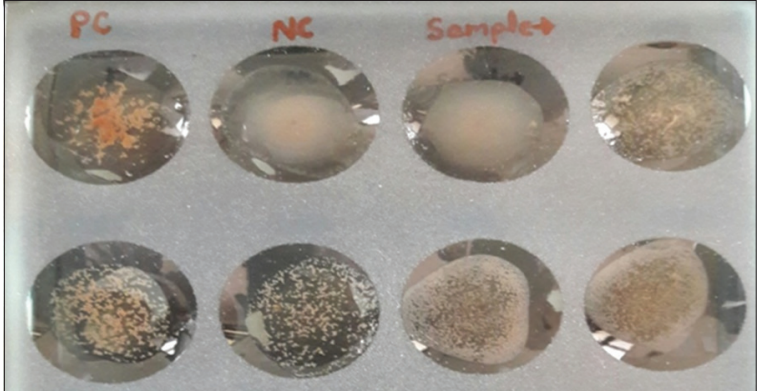

Fig. 3: Hemagglutination assay by slide method. PC: Positive control, NC: Negative control

with lower immunity. This study has shown hypermucoviscosity was positive in some isolates which are emerging virulent traits of Klebsiella because of increased capsule production ability. In case of Fimbriae detection, type 3 was the most common as compared to type 1 , which might be the major cause of biofilm production in Klebsiella infection and one of the major causes of emerging drug resistance.

\section{ACKNOWLEDGMENT}

We would like to acknowledge Varsha Saxena (PhD Scholar, Department of Microbiology) for her support, Department of Microbiology, Yenepoya Research Center, for supporting this study and Yenepoya University, for providing seed grant for this study.

\section{AUTHOR'S CONTRIBUTION}

Jitendra Chandra Devrari has contributed to the study conception, design, sample collection, analysis and interpretation of the data and manuscript preparation. Vidya Pai has contributed to the study conception and critical revision of the manuscript.

\section{CONFLICT OF INTERESTS}

None.

\section{REFERENCES}

1. Mulla S, Kumar A, Rajdev S. Comparison of MIC with MBEC assay for in vitro antimicrobial susceptibility testing in biofilm forming clinical bacterial isolates. Adv Microbiol 2016;6:73-8.

2. Jonnalagadda S, Deshabathini UK. Anti-Quorum sensing potential of Moringa oleifera seed extract. Int J Pharm Pharm Sci 2016;8:76-82.

3. Schroll C, Barken KB, Krogfelt KA, Struve C. Role of Type 1 and
Type 3 fimbriae in Klebsiella pneumoniae biofilm formation. BMC Microbiol 2010;10:179.

4. Kumar E, Usha K, Ramana BV, Chaudhury A, Sai Gopal DV. Plasmid profile and curing, biofilm detection among ESBL producing isolates of Acinetobacter species. Int J Pharm Pharm Sci 2016;8:39-42.

5. Shon AS, Bajwa RP, Russo TA. Hypervirulent (hypermucoviscous) Klebsiella pneumonia A new and dangerous breed. Virulence 2013;4:107-18.

6. Vuotto C, Longo F, Balice MP, Donelli G, Varaldo PE. Antibiotic resistance related to biofilm formation in Klebsiella pneumoniae. Pathogens 2014;3:743-58.

7. Podschun R, Ullmann U. Klebsiella spp. As nosocomial pathogens: Epidemiology, taxonomy, typing methods, and pathogenicity factors. Clin Microbiol Rev 1998;11:589-603.

8. Collee JG. Mackie and McCartney Practical Medical Microbiology. $14^{\text {th }}$ ed. London: Churchill Livingstone. 1996; 17-30.

9. Clinical and Laboratory Standards Institute (CLSI). Performance Standards for Antimicrobial Susceptibility Testing; Twenty Six Informational Supplement. Vol. 30, M100-S26. Wayne, Pa, USA: CLSI; 2016.

10. Aljanaby AA, Alhasani AH. Virulence factors and antibiotic susceptibility patterns of multidrug resistance Klebsiella pneumoniae isolated from different clinical infections. Afr J Microbiol Res 2016; $10: 829-43$

11. O'Toole GA, Kolter R. Initiation of biofilm formation in Pseudomonas fluorescens WCS 365 proceeds via multiple convergent signaling pathways, A genetic analysis. Mol Microbiol 1998;28:449-61.

12. Duguid JP. Firnbriae and adhesive properties in Klebsiella strains. J Gen Microbiol 1959;21:271-86.

13. Schwyn B, Neilands JB. Universal chemical assay for the detection and determination of siderophores. Anal Biochem 1987;160:47-56.

14. Nakkash AF, Al-Husseiny KR. Study some virulence factors of Klebsiella pneumoniae isolated from clinical sources. J Thi Qar Univ 2008;3:45-50.

15. Namikawa H, Yamada K, Fujimoto H, Oinuma KI, Tochino Y, Takemoto $\mathrm{Y}$, et al. Two unusual cases of successful treatment of hypermucoviscous Klebsiella pneumoniae invasive syndrome. BMC Infect Dis 2016;16:680.

16. Tarkkanen AM, Allen BL, Williams PH, Kauppi M, Haahtela K, Siitonen A, et al. Fimbriation, capsulation, and iron-scavenging systems of Klebsiella Strains associated with human urinary tract infection. Infect Immun 1992;60:1187-92.

17. Chaudhary NK, Murthy SM. Urinary tract infection: Etiology and antimicrobial resistance with reference to adhesive organelles. J Drug Deliv Ther 2013;3:93-8.

18. Podschun R, Fischer A, Ullman U. Expression of putative virulence factors by clinical isolates of Klebsiella planticola. J Med Microbiol 2000;49:115-9.

19. Pramodhini S, Niveditha S, Umadevi S, Kumar S, Stephen S. Antiobiotic resistance pattern of biofilm-forming uropathogens isolated from catheterized patients in Pondicherry. Aust Med J 2012;5:344-8. 